\title{
Three-dimensional architecture of the neurovascular and adipose zones of the upper and lower lumbar intervertebral foramina: an epoxy sheet plastination study
}

\author{
*Zhaoyang Xu, MB, MMed, ${ }^{1,2}$ Guoxiong Lin, MB, ${ }^{1}$ Han Zhang, ${ }^{3}$ Shengchun Xu, MB, MMed, ${ }^{1}$ and \\ Ming Zhang, MB, MMed, PhD²
} 'Department of Anatomy, Anhui Medical University, Hefei, China; ${ }^{2}$ Department of Anatomy, University of Otago; and ${ }^{3}$ School of
Medicine, University of Otago, Dunedin, New Zealand

\begin{abstract}
OBJECTIVE Kambin's triangle and the safe triangle are common posterolateral approaches for lumbar transforaminal endoscopic surgery and epidural injection. To date, no consensus has been reached on the optimal transforaminal approach, in particular its underlying anatomical mechanism. The aim of this study was to investigate the 3D architecture of the neurovascular and adipose zones in the upper and lower lumbar intervertebral foramina (IVFs).
\end{abstract}

METHODS Using the epoxy sheet plastination technology, 22 cadaveric lumbar spines (12 female and 10 male, age range $46-89$ years) were prepared as a series of transverse (11 sets), sagittal (8 sets), and coronal ( 3 sets) slices with a thickness of $0.25 \mathrm{~mm}$ ( 6 sets) or $2.5 \mathrm{~mm}$ ( 16 sets). The high-resolution images of the slices were scanned and analyzed. The height, area, and volume of 30 IVFs from T12-L1 to L4-5 were estimated and compared. This study was performed in accord with the authors' institutional ethical guidelines and approved by the institutional ethics committees.

RESULTS The findings were as follows. 1) The 3D boundaries of the lumbar IVF and its subdivisions were precisely defined. 2) The 3D configuration of the neurovascular and adipose zones was different between the upper and lower lumbar IVFs; zoning in the upper lumbar IVFs was much more complex than that in the lower lumbar IVFs. 3) In general, the infraneural adipose zone gradually tapered and rotated from the inferoposterolateral aspect to the superoanteromedial aspect. 4) The average height, area, and volume of the IVF gradually increased from the upper to the lower lumbar spine. Within a lumbar IVF, the volumes below and above the inferior border of the dorsal root ganglia were similar.

CONCLUSIONS This study highlights differences of fine 3D architecture of neurovascular and adipose tissues between the upper and lower lumbar IVFs, with related effects on the transforaminal approaches. The findings may contribute to optimization of the surgical approaches to and through the IVF at different lumbar spinal levels and also may help to shorten the learning curve for the transforminal techniques.

https://thejns.org/doi/abs/10.3171/2019.10.SPINE191164

KEYWORDS anatomy; lumbar intervertebral foramina; transforaminal approach; Kambin's triangle; epoxy sheet plastination

$\mathrm{T}$ RANSFORAMINAL endoscopic surgery and epidural injection have been increasingly used by spine surgeons, interventional radiologists, anesthetists, and pain physicians. ${ }^{6,9,21,23,29,36}$ Common posterolateral approaches to the lumbar intervertebral foramina (IVFs) are the Kambin's triangle approach and the safe triangle approach. ${ }^{15,29,32}$ Kambin's triangle was originally defined as an extrapedicular working zone on a posterolateral view at $35^{\circ}-45^{\circ}$, bordered by the exiting spinal nerve anteriorly, the superior articular process (SAP) posteriorly, and the superior margin of the lower vertebra inferiorly. ${ }^{13,14,16}$ The currently described Kambin's triangle has been expanded as a 3D access corridor to the intraforaminal and spinal canal areas. The boundaries of this 3D corridor are the dural sac and traversing nerve roots medially, the exiting spinal nerve superiorly, the superior margin of the lower vertebra inferiorly, the intervertebral disc (IVD) and vertebral bodies anteriorly, and the SAP posteriorly., $73,25,29,32$ The "safe triangle" is a subpedicular zone bounded by the upper vertebral body anteriorly, the inferior margin of its

ABBREVIATIONS DRG = dorsal root ganglion; IVD = intervertebral disc; IVF = intervertebral foramen; IVJ = intervertebral joint; PA = posteroanterior; SAP = superior

articular process; TFB = transforaminal fibrous bundle.

SUBMITTED September 24, 2019. ACCEPTED October 28, 2019.

INCLUDE WHEN CITING Published online January 10, 2020; DOI: 10.3171/2019.10.SPINE191164.

* Z.X. and G.L. contributed equally to this work. 
pedicle superiorly, and the exiting spinal nerve inferiorly. ${ }^{4,6,29}$ Kambin's triangle is used for both endoscopic surgery and epidural injection, ${ }^{29,32}$ whereas the safe triangle is used for epidural injections only. ${ }^{29}$

Despite the fact that the efficacy, safety, and optimal surgical procedures of Kambin's triangle and the safe triangle have been extensively studied and compared, ${ }^{17,25,28}$ no consensus has been reached on the optimal transforaminal approach-in particular its underlying anatomical mechanism. ${ }^{6,27,32}$ For example, the safe working space of Kambin's triangle is restricted by the neural structures and varies between spinal levels.19,32 Because of the surgical complications caused by the restricted space, some authors refrain from recommending this transforaminal technique unless "decisive technical improvements" were to be made..$^{12}$ It has also been argued that the safe triangle is not in fact safe because it contains rich neurovascular structures that are prone to be injured. ${ }^{6}$

A thorough knowledge of the underlying 3D IVF anatomy is paramount to developing proficient technical skills and to avoid dural, neural, and vascular injuries during the transforaminal approach.,33 So far, several clinical and anatomical studies have investigated the extent of the safe zone in the IVF. ${ }^{7,10,25,37}$ However, those studies mainly focused on its dimensions ${ }^{8}$ and cross-sectional areas ${ }^{5}$ along either sagittal ${ }^{7,24}$ or coronal ${ }^{25}$ planes rather than investigating in a 3D space. ${ }^{18}$ In addition, deformation of nerves and other structures during dissection might have biased the estimated data. ${ }^{24}$ Moreover, very few studies defined the fine configuration of neurovascular and adipose tissues in the IVFs and their relationship with the surrounding structures, e.g., vertebral bodies, pedicles, SAP, IVD, intervertebral joint (IVJ), ligamenta flava, dural sac, and spinal epidural space, particularly at different levels of the lumbar spine.

Technically, the study of the soft-tissue architecture is complicated by the fact that great difficulties exist in dissecting out fine structures. Although histological examination may be able to overcome the problem, the application of such a method is greatly limited by the size of sample areas, alteration of tissue architecture during decalcification, and difficulty in tracing the origin of a structure. These limitations are largely overcome by the newly developed technology of epoxy sheet plastination, which not only ensures preservation of the in situ position of bones, cartilages, and soft tissues without decalcification but also allows these structures to be examined undisturbed in their natural state at both the macroscopic and microscopic levels. ${ }^{26,35}$ Therefore, the aim of this study was to investigate the 3D architecture of the neurovascular and adipose zones in the upper and lower lumbar IVFs.

\section{Methods}

A total of 22 embalmed cadavers (12 female and 10 male, age range 46-89 years) were used in this study. None of the cadavers had any known history of spinal injury or surgery. Approval for the use of the cadavers was granted by the University of Otago Human Ethics Committee (Health) in conjunction with Māori consultation being sought from the Ngāi Tahu Research Consultation Committee, and by the Medical Ethics Committee of Anhui Medical University.

\section{Epoxy Sheet Plastination and Staining}

In 16 of the 22 examined cadavers, lumbar spines were prepared as a series of transverse (10 sets), sagittal (5 sets), and coronal (1 set) slices by using the epoxy sheet plastination procedure as previously described.$^{35}$ In brief, the specimen was frozen at $-80^{\circ} \mathrm{C}$ for 7 days and then sliced with a band saw. The slice thickness was $2.5 \mathrm{~mm}$ and the interval between adjacent slices was $0.9 \mathrm{~mm}$. The slices were dehydrated in $-30^{\circ} \mathrm{C}$ acetone for 4 weeks, followed by degreasing in acetone at room temperature for 3-4 weeks, and impregnated with an epoxy resin mixture of E12/E1/AE20/AE30 (Biodur) at $0^{\circ} \mathrm{C}$ for 24 hours. The impregnated slices were cast with plastic sheets. The cast slices were hardened at $60^{\circ} \mathrm{C}$ for 5 days. The high-resolution images of the slices were scanned with an Epson Perfection V750 Pro Scanner (Epson).

The other 6 spines were prepared as ultrathin plastinated slices with a thickness of $0.25 \mathrm{~mm}$. Compared with the plastination procedures described above, the main differences with this technique were a longer dehydration and degreasing period (4-6 months) and a different epoxy resin mixture (E12/E6/E600; Biodur). Each specimen was plastinated as a single block first. The plastinated block was sectioned as a series of transverse (1 set), sagittal (3 sets), and coronal (2 sets) slices by using the Exakt $310 \mathrm{CP}$ Cutting System (Exakt). The ultrathin slices were stained with Stevenel's Blue and Alizarin Red S. The images were scanned as described above.

\section{Three-Dimensional Reconstruction of the Lumbar IVF}

To help the understanding and interpretation of those 2D plastinated slices, the 3D architecture of one L2-3 IVF was reconstructed from 29 serial ultrathin sections at the level of L2-3 of one transverse set. The lumbar vertebrae, IVDs, dural sac, spinal nerves, vessels, and adipose tissue space were manually segmented and then reconstructed and displayed as 3D images in Thermo Scientific Amira Software (Amira 6.9.0; Thermo Fisher Scientific).

\section{Quantification of the Lumbar IVF}

The volume of the lumbar IVF was estimated in 30 IVFs in 3 transverse sets of the plastinated slices. Each set included 10 IVFs (5 pairs) from T12-L1 to L4-5. The area of the IVF on a transverse section was measured in the ImageJ software (an open source Java image processing program inspired by NIH Image; https://imagej.net/ ImageJ). The height of an IVF was estimated by multiplying the number of the sections that contained the IVF by the thickness of the section and the interval. The volume of the IVF was estimated by multiplying the average area of the lumbar IVF by the height.

\section{Statistical Analysis}

Quantitative data were analyzed using the SPSS version 25 software (IBM Corp.) and reported as the mean \pm $\mathrm{SD}$. The Kolmogorov-Smirnov test was used to test nor- 


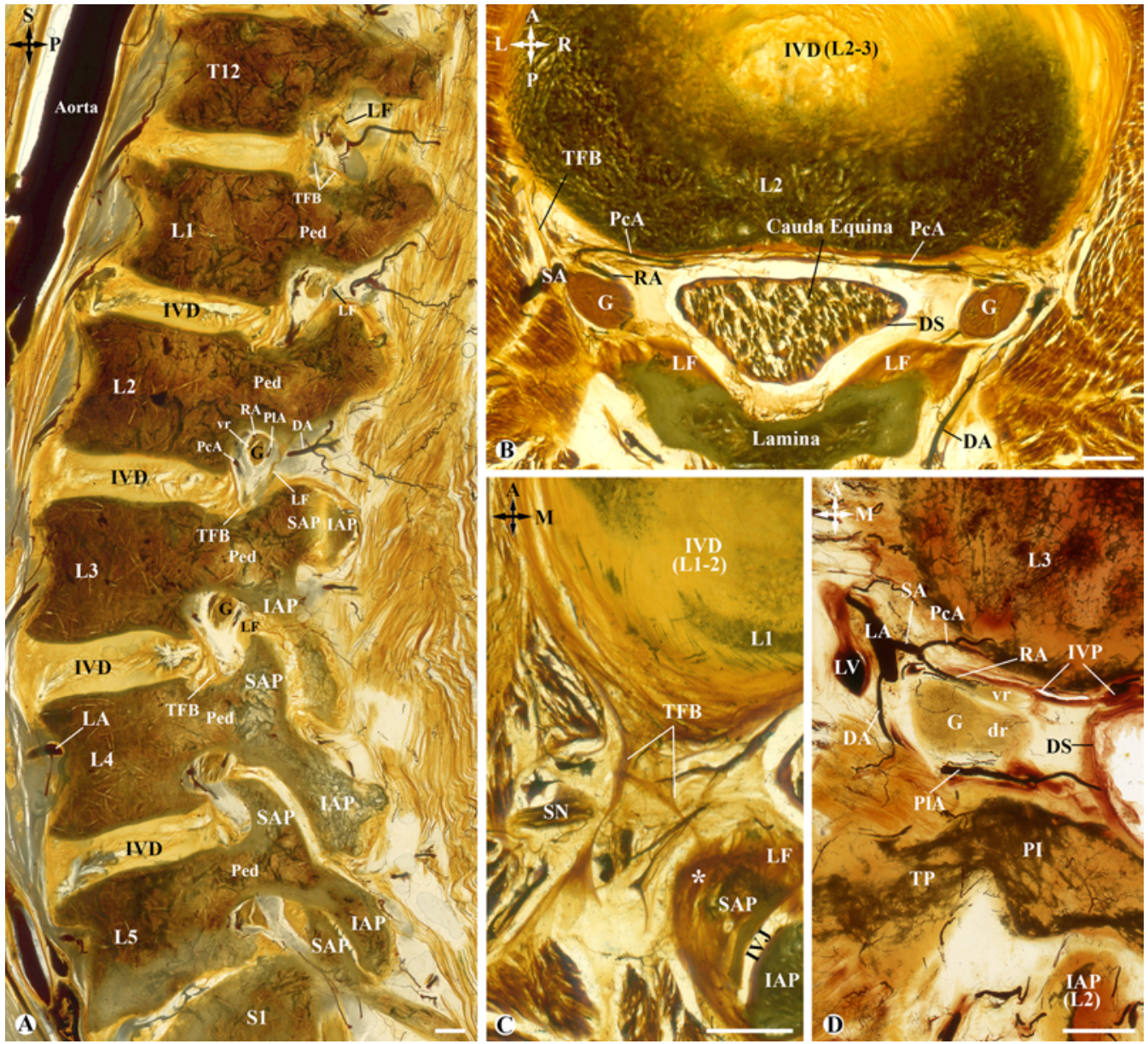

FIG. 1. Sagittal (A) and transverse (B-D) views of the lumbar IVFs. A: A sagittal plastinated section showing the lumbar IVFs. The transforaminal structures and borders of the L2-3 IVF are labeled in detail. B-D: Three transverse plastinated sections at the level of the superior endplate of the IVD where the DRG $(G)$ of the spinal nerve (SN) (panel B), TFBs of the anulus fibrosus (panel C), and spinal artery (SA) and its 3 main branches (panel D) are located. The asterisk in panel $\mathrm{C}$ indicates the fibrous capsule of the IVJ, which is contributed by the ligamenta flava (LF). DA = dorsal branch of lumbar artery; $d r=$ dorsal root of spinal nerve; DS = dural sac; IAP = inferior articular process; IVP = internal vertebral venous plexus; LA = lumbar artery; LV = lumbar vein; $\mathrm{PcA}=$ postcentral branch of spinal artery; $\mathrm{Ped}=$ pedicle; $\mathrm{PI}=$ pars interarticularis; $\mathrm{PIA}=$ prelaminar branch of spinal artery; $\mathrm{RA}=$ radicular branch of spinal artery; $\mathrm{TP}=$ transverse process; $\mathrm{vr}=$ ventral root of spinal nerve. Crossed arrows show the orientation of the figure $(S=$ superior; $P=$ posterior; $L=$ left; $R=$ right; $A=$ anterior; $M=$ medial). $B a r=5 \mathrm{~mm}$. Figure is available in color online only.

mality of data. The 1-way ANOVA test and the Tukey test were used for comparing the overall difference and a difference between two groups. The Pearson correlation was used for evaluating the correlations among the variables.

\section{Results}

\section{Boundaries of the Lumbar IVF}

The anterior, posterior, superior, and inferior boundaries of the IVF were the vertebral bodies and IVD, the SAP, and the ligamenta flava, which contributed to the anterior fibrous capsule of the IVJ, the upper pedicle, and the lower pedicle, respectively (Fig. 1A and B).

The lateral boundary of the IVF was defined as a sagittal plane that passed from the posterolateral margin of the vertebral body and IVD to the most lateral aspect of the
IVJ. The medial boundary of the IVF was a sagittal plane that was parallel to the lateral boundary and passed the most lateral aspect of the dural sac (Fig. 2).

\section{Subdivisions of the Lumbar IVF}

A horizontal level along the inferior border of the dorsal root ganglion (DRG) was used to subdivide the IVF into a superior and an inferior compartment. This was based on 3 anatomical considerations. 1) Of the 89 lumbar IVFs from the 13 cadavers examined in this study, all the DRGs were within the foramina, and the inferior border of the majority of the DRGs ( 85 of 89) was at or above the level of the superior endplate of the IVD (Table 1). 2) At this level, transforaminal fibrous bundles (TFBs) from the anulus fibrosus were anchored to the pars interarticularis and the neighboring fibrous capsule of the IVJ, the liga- 
Xu et al.

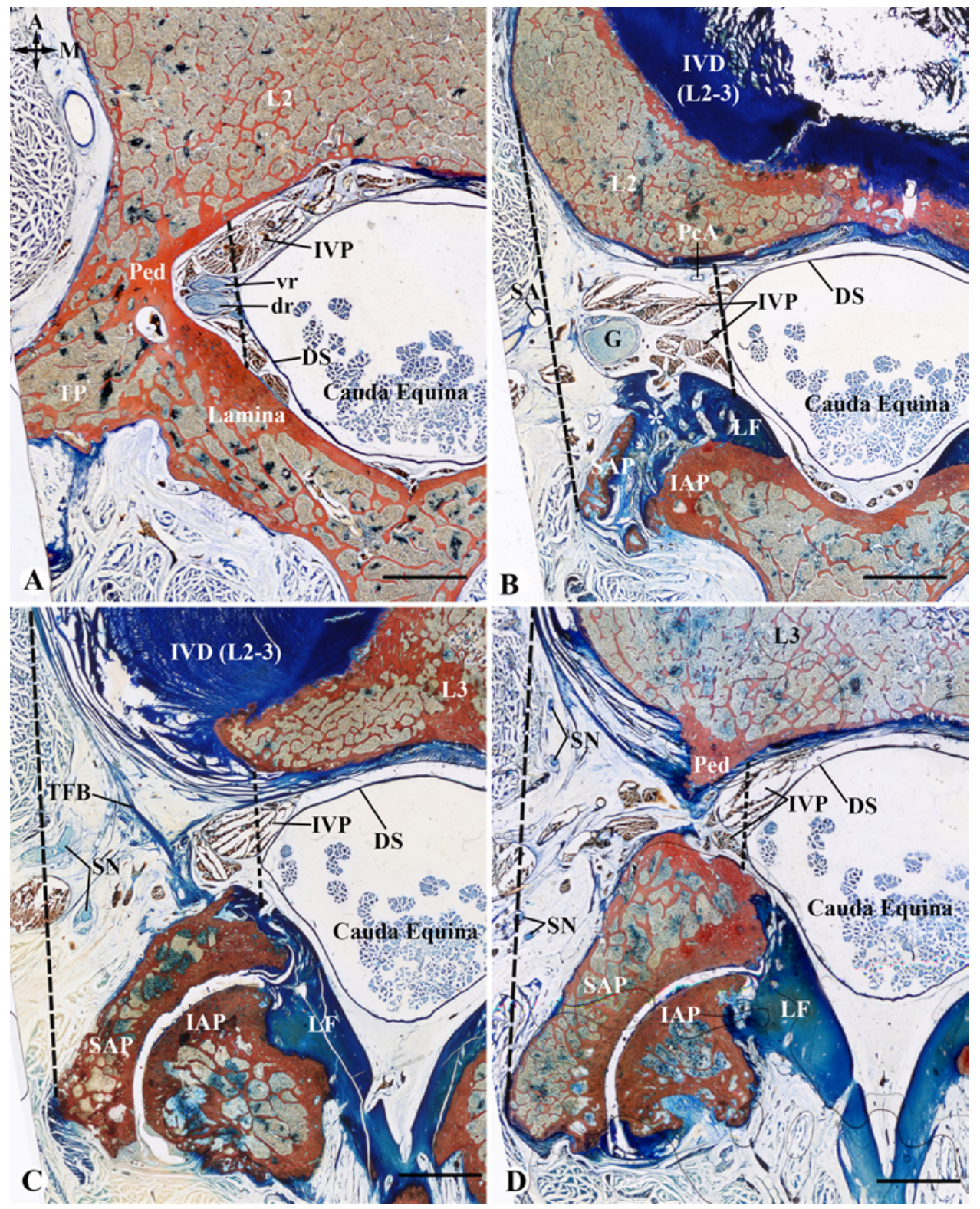

FIG. 2. Four serial transverse plastinated sections at the levels of the superomedial extension (A), superior (B), and inferior (C and D) compartments of the L2-3 IVF, showing its medial and lateral boundaries (dashed lines) defined in this study. The sections were stained with Stevenel's Blue and Alizarin Red S. dr = dorsal root of spinal nerve; DS = dural sac; G = DRG; IAP = inferior articular process; IVP = internal vertebral venous plexus; LF = ligamenta flava; PcA = postcentral branch of spinal artery; Ped = pedicle; $\mathrm{SN}=$ spinal nerve; $\mathrm{TP}=$ transverse process; $\mathrm{vr}=$ ventral root of spinal nerve. Crossed arrows show the orientation of the figure $(A=$ anterior; $M=$ medial). Bar $=5 \mathrm{~mm}$. Figure is available in color online only.

menta flava, SAP, transverse process, and pedicle (Figs. $1 \mathrm{C}$ and 2C).3) Around this level, the spinal artery gave off its transforaminal branches (Fig. 1D).

In the lumbar spine, the anterior and posterior roots of the spinal nerve and the associated dural sleeve traversed the epidural space superiorly beyond the inferior margin of the upper pedicle. Thus, the part of the epidural space between the opening of the dural sleeve and the inferior margin of the upper pedicle was termed the superomedial extension of the IVF (Fig. 2A).

\section{Neurovascular and Adipose Zones in the Lumbar IVF}

The 3D configuration and localization of the neurovascular and adipose zones in the IVF were different between the upper (Fig. 3A, B, and D-G) and lower (Fig. 3C and $\mathrm{H}-\mathrm{K})$ lumbar spine. To help better understand and interpret those 2D sectional images, a 3D image of an L2-3 IVF was reconstructed from a series of $0.25-\mathrm{mm}$-thick transverse sections and illustrates the general fine configuration of the IVF (Fig. 4A-E). In particular, the infraneural adipose zone was a main adipose corridor in a lum- 
Xu et al.

TABLE 1. Correspondence between the inferior border of the DRG and the superior endplate of the IVD

\begin{tabular}{ccccc}
\hline Superior Endplate & Above & At & Below & Total \\
\hline T12-L1 & 8 & 1 & & 9 \\
\hline L1-2 & 6 & 4 & & 10 \\
\hline L2-3 & 11 & 1 & 2 & 14 \\
\hline L3-4 & 15 & 2 & 1 & 18 \\
\hline L4-5 & 17 & 2 & 1 & 20 \\
\hline L5-S1 & 17 & 1 & & 18 \\
\hline Total & 74 & 11 & 4 & 89 \\
\hline
\end{tabular}
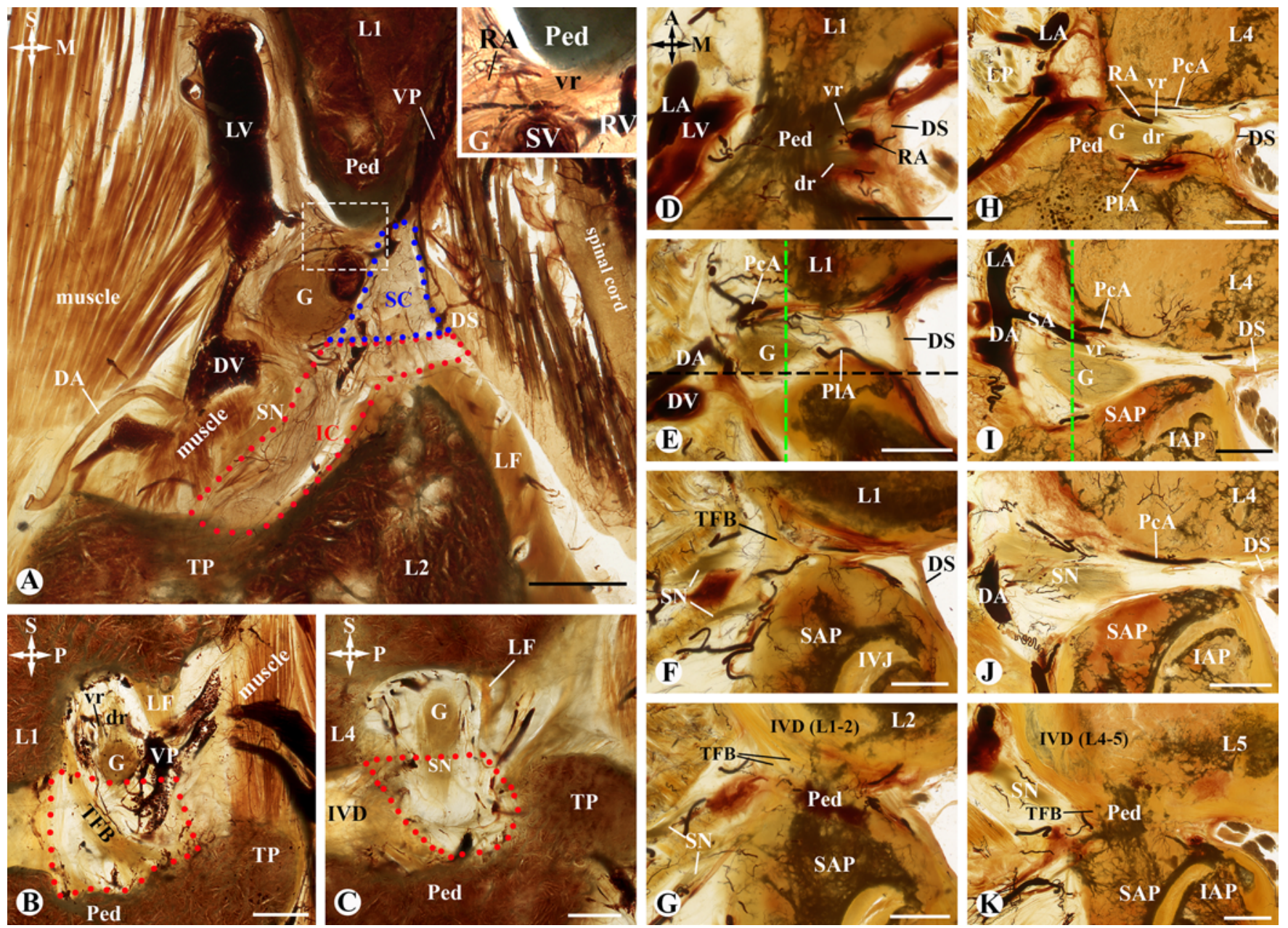

bar IVF and gradually tapered and rotated from the inferoposterolateral aspect to the superoanteromedial aspect (see Fig. 4E for its 3D view and Fig. 3A for its 2D coronal view). The visualization of this infraneural adipose zone varied at different angles (Fig. 5A-D). An optimal angle to visualize the zone ranged from $45^{\circ}$ to $60^{\circ}$ in reference to the posteroanterior (PA) axis and the posterior coronal plane of the IVD (Figs. 4E and 5B).

\section{Fine Architecture in the Upper Lumbar Spine (IVFs L1-2 and L2-3)}

In the superomedial extension, the roots and vessels

FIG. 3. Comparison of the architecture and location of neurovascular and adipose zones between the upper (A, B, D-G) and lower (C, $\mathrm{H}-\mathrm{K}$ ) lumbar IVFs. A: A coronal plastinated section of the L1-2 IVF at the level indicated by the black dashed line in panel $\mathrm{E}$. The colored dots outline an infraneural adipose zone in the inferior (IC; red dots) and superior (SC; blue dots) compartments. The inset is a highermagnification $(\times 4.5)$ view of the dashed line box in panel A, showing the neurovascular structures within the area of the "safe" triangle. B: A sagittal plastinated section of the L1-2 IVF at the level indicated by the green dashed line in panel $\mathrm{E}$, showing that the adipose zone in the inferior compartment (red dots) is further compartmentalized by the TFBs. C: A sagittal plastinated section of the L4-5 IVF at the level indicated by the green dashed line in panel I, showing that the adipose zone (red dots) occupies its inferior compartment. D-G and H-K: Four pairs of serial transverse plastinated sections at the levels of the superomedial extension ( $D$ and $H)$, superior $(E$ and $I)$ and inferior ( $F$ and $G$, J and K) compartments of the L1-2 (D-G) or L4-5 (H-K) IVF. DA = dorsal branch of lumbar artery; dr = dorsal root of spinal nerve; $D S=$ dural sac; $D V=$ dorsal tributary of lumbar vein; $G=D R G ; I A P=$ inferior articular process; $L A=$ lumbar artery; $L F=$ ligamenta flava; LP = lumbar plexus; $L V=$ lumbar vein; $P c A=$ postcentral branch of spinal artery; Ped = pedicle; PIA = prelaminar branch of spinal artery; RA = radicular branch of spinal artery; RV = radicular vein; SA = spinal artery; SN = spinal nerve; SV = spinal vein; TP $=$ transverse process; $V P=$ vertebral venous plexus; $v r=$ ventral root of spinal nerve. Crossed arrows show orientation of the figure $(S=$ superior; $\mathrm{M}=$ medial; $\mathrm{P}=$ posterior; $\mathrm{A}=$ anterior). $\mathrm{Bar}=5 \mathrm{~mm}$. Figure is available in color online only. 

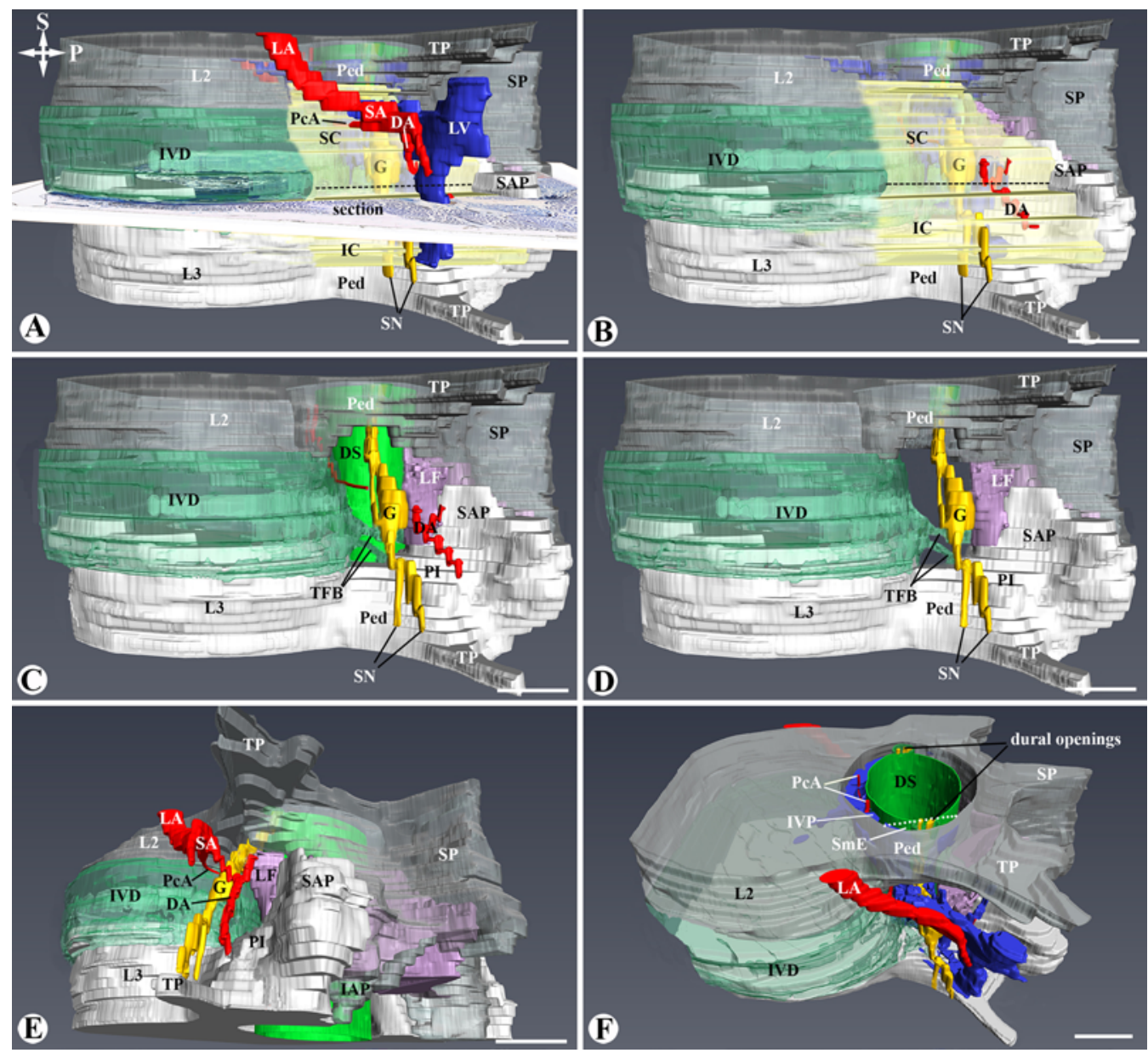

FIG. 4. A 3D image of the architecture of the L2-3 IVF. A: A lateral view of the image, which was reconstructed from a series of the plastinated horizontal sections. The dashed line indicates the level of the inferior border of the DRG $(G)$, which is the demarcation between the superior (SC) and inferior (IC) compartments of the IVF. B: Same as panel A, but without the vessels outside the IVF. The light yellow color highlights the 3D IVF defined in this study. C and D: The main transforaminal neural and arterial structures and TFB of the anulus fibrosus in the IVF. E: A posteroinferolateral view of the IVF with the extraforaminal arterial structures at $45^{\circ}$ in reference to the PA axis and the posterior coronal plane of the IVD, showing the infraneural adipose corridor. F: A superolateral view of the superomedial extension (SmE) of the IVF, in which the medial border is indicated by a dotted line. DA = dorsal branch of lumbar artery; $D S=$ dural sac; IAP = inferior articular process; IVP = intervertebral venous plexus; $L A=$ lumbar artery; $L F=$ ligamenta flava; $\mathrm{LV}=$ lumbar vein; $\mathrm{PcA}=$ postcentral branch of spinal artery; Ped = pedicle; $\mathrm{PI}=$ pars interarticularis; $\mathrm{SA}=\mathrm{spinal}$ artery; $\mathrm{SN}=$ spinal nerve; $\mathrm{SP}=$ spinous process; $\mathrm{TP}=$ transverse process. Crossed arrows show orientation of the figure $(\mathrm{S}=$ superior; $P=$ posterior). $B a r=10 \mathrm{~mm}$. Figure is available in color online only.

were enclosed within a dural sleeve (Figs. 2A and 3D), traversed the epidural space, and entered the superior compartment along the inferior margin of the pedicle (Fig. $3 \mathrm{~A})$. The epidural space was almost fully occupied by the venous plexus with sparse adipose tissue (Figs. 2A, 3A, and $3 \mathrm{D})$.

In the superior compartment, the nerve roots, DRG, and vessels traveled obliquely in an inferoanterolateral direction and occupied the most space (Figs. 1B, 1D, 2B, 3A, $3 \mathrm{~B}$, and $3 \mathrm{E}$ ). The adipose zone was mainly localized medial and inferior to the nerve roots and DRG (Figs. 1B, 1D, $3 \mathrm{~A}, 3 \mathrm{E}$, and $4 \mathrm{E}$ ). The space of the "safe" triangle, which was anterior and superior to the neural structures, was very limited and fully occupied by the radicular and postcentral arteries and venous plexus (Figs. 1B, 1D, and 3A inset).
In the inferior compartment, the TFBs of the anulus fibrosus further compartmentalized the region into a small anteroinferior adipose pocket and a large posterosuperior neurovascular zone (Fig. 3A, B, and F). The spinal nerve passed the edge of the neurovascular zone (Fig. 4A and $\mathrm{B})$. The remaining space of the neurovascular zone was occupied by the venous plexus (Figs. 3B and 4F) and the adipose tissue, which was continuous with the aforementioned large adipose zone in the superior compartment (Fig. 3A).

The TFBs of the anulus fibrosus in the upper lumbar IVFs were intermingled with the neurovascular sheaths (Fig. 1C) and anchored to the fibrous capsule, ligamenta flava (Fig. 2C), SAP, transverse processes (Fig. 3B and G), and pedicle (Fig. 3G). 

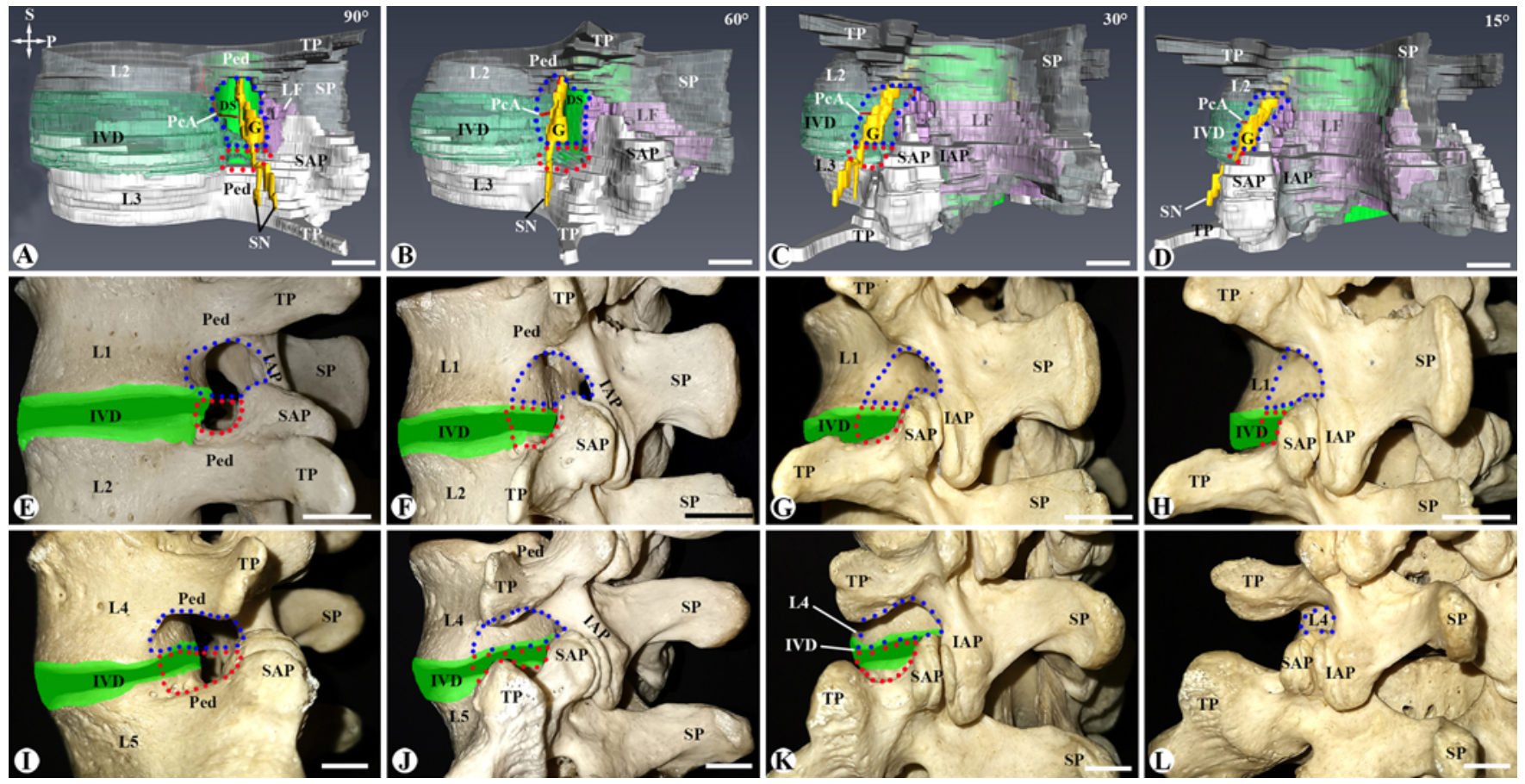

FIG. 5. Visualization of the superior (blue dashed circles) and inferior (red dashed circles) compartments of the lumbar IVFs from $90^{\circ}$ to $15^{\circ}$ in reference to the PA axis and the posterior coronal plane of the IVD. The upper row (A-D) is the 3D reconstructed image of an L2-3 IVF as shown in panel C, but without the dorsal artery. The middle $(\mathrm{E}-\mathrm{H})$ and lower $(\mathrm{I}-\mathrm{L})$ rows are the $\mathrm{L} 1-2$ and L4-5 IVFs displayed in the skeletal lumbar spine. DS = dural sac; G = DRG; IAP = inferior articular process; LF = ligamenta flava; $\mathrm{PcA}=$ postcentral branch of spinal artery; $\mathrm{Ped}=$ pedicle; $\mathrm{SN}=$ spinal nerve; $\mathrm{SP}=$ spinous process; $\mathrm{TP}=$ transverse process. Crossed arrows show orientation of the figure $(S=$ superior; $P=$ posterior). Bar $=10 \mathrm{~mm}$. Figure is available in color online only.

Fine Architecture in the Lower Lumbar Spine (IVFs L3-4 and L4-5)

Compared to the upper lumbar spine, the configuration and location of the neurovascular and adipose zones in the lower lumbar spine displayed 3 main differences (Figs. $1 \mathrm{~A}, 3 \mathrm{C}$, and $3 \mathrm{H}-\mathrm{K})$. 1) The adipose tissue almost fully occupied the inferior compartment (Figs. 1A and 3C), and the TFBs were anchored to the anterior part of the pedicle only (Figs. 1A and 3K). 2) The neurovascular structures were limited within the superior compartment (Figs. 1A, 3C, and 3I). 3) A single infraneural adipose zone gradually tapered and rotated from the inferior compartment (Fig. $3 \mathrm{C}$ ) to the medial part of the superior compartment (Fig. $3 \mathrm{I}$ and $\mathrm{J}$ ) and further to the superomedial extension (Fig. $3 \mathrm{H})$.

\section{Volumes of the Lumbar IVF and Its Subcompartments}

From the upper to the lower lumbar spine, the average height, area, and volume of the IVF gradually increased ( $p<0.001$ ) (Table 2 and Fig. 6). The increase in volume of the IVF from the upper to lower lumbar spine was correlated with that of the subcompartments of the IVF $(r=$ 0.746, 0.917, and 0.919, respectively; p < 0.001) (Fig. 6 and Table 2). No difference was found between the left and right sides $(p=0.906)$.

Within a lumbar IVF, the volumes of the superior and inferior compartments were similar $(\mathrm{p}>0.05)$ (Table 2 and Fig. 6). The proportion of the superomedial extension was very small in the upper lumbar IVFs $(4 \%-6 \%)$ but relatively larger in the lower lumbar IVFs (12\%-18\%) (Table 2). Its height ranged from $3.4 \mathrm{~mm}$ in the upper lumbar spine to $6.8-10.2 \mathrm{~mm}$ in the lower lumbar spine.

\section{Discussion}

Despite many benefits, transforaminal endoscopic surgery and epidural injection do have limitations and drawbacks. A thorough knowledge of the 3D anatomy of the lumbar IVF is paramount to negotiate a steep learning curve of the techniques and to avoid dural, neural, and vascular injuries., ${ }^{3,33}$ Using the novel epoxy sheet plastination technology, this study precisely defined the 3D boundaries of the lumbar IVF and its subdivisions, identified the fine configuration of the neurovascular and adipose zones, and revealed the differences between the upper and lower lumbar spine. To help better understand and interpret those 2D sectional images and conceptualize an optimal transforaminal approach from a 3D perspective, the 3D architecture of one L2-3 IVF was reconstructed as an illustration instead of a commonly used drawing (Figs. 4 and 5).

\section{Three-Dimensional Boundaries of the Lumbar IVF}

To understand the 3D architecture of the IVF, it is necessary to define its 3D boundaries. The superior, inferior, anterior, and posterior boundaries of the IVF have been well documented. ${ }^{31}$ However, confusion arises regarding 
TABLE 2. The average height, area, and volume of the IVF

\begin{tabular}{|c|c|c|c|c|}
\hline IVF* $^{*}$ & SmE & SC & IC & Total \\
\hline \multicolumn{5}{|l|}{ T12-L1 } \\
\hline Height (mm) & $3.4 \pm 0.0$ & $7.9 \pm 1.8$ & $7.4 \pm 1.4$ & $18.7 \pm 2.8$ \\
\hline Area $\left(\mathrm{mm}^{2}\right)$ & $18.0 \pm 9.0$ & $67.0 \pm 3.0$ & $93.0 \pm 15.0$ & $67.0 \pm 11.0$ \\
\hline Vol $\left(\mathrm{mm}^{3}\right)$ & $60.0 \pm 30.0$ & $520.0 \pm 70.0$ & $670.0 \pm 110.0$ & $1230.0 \pm 160.0$ \\
\hline Proportion of total vol & $5 \%$ & $41 \%$ & $54 \%$ & $100 \%$ \\
\hline \multicolumn{5}{|l|}{ 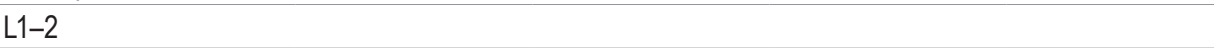 } \\
\hline Height (mm) & $3.4 \pm 0.0$ & $7.9 \pm 1.8$ & $9.1 \pm 1.8$ & $20.4 \pm 3.0$ \\
\hline Area $\left(\mathrm{mm}^{2}\right)$ & $23.0 \pm 14.0$ & $72.0 \pm 13.0$ & $79.0 \pm 18.0$ & $64.0 \pm 11.0$ \\
\hline Vol $\left(\mathrm{mm}^{3}\right)$ & $80.0 \pm 47.0$ & $570.0 \pm 110.0$ & $690.0 \pm 120.0$ & $1300.0 \pm 180.0$ \\
\hline Proportion of total vol & $6 \%$ & $42 \%$ & $52 \%$ & $100 \%$ \\
\hline \multicolumn{5}{|l|}{ L2-3 } \\
\hline Height (mm) & $3.4 \pm 0.0$ & $9.1 \pm 0.2$ & $10.8 \pm 1.4$ & $23.2 \pm 2.6$ \\
\hline Area $\left(\mathrm{mm}^{2}\right)$ & $23.0 \pm 10.0$ & $91.0 \pm 12.0$ & $85.0 \pm 18.0$ & $77.0 \pm 12.0$ \\
\hline $\operatorname{Vol}\left(\mathrm{mm}^{3}\right)$ & $80.0 \pm 30.0$ & $830.0 \pm 200.0$ & $920.0 \pm 220.0$ & $1800.0 \pm 410.0$ \\
\hline Proportion of total vol & $4 \%$ & $46 \%$ & $50 \%$ & $100 \%$ \\
\hline \multicolumn{5}{|l|}{ L3-4 } \\
\hline Height (mm) & $6.8 \pm 0.0$ & $7.9 \pm 1.8$ & $11.3 \pm 1.8$ & $26.1 \pm 3.5$ \\
\hline Area $\left(\mathrm{mm}^{2}\right)$ & $40.0 \pm 7.0$ & $108.0 \pm 8.0$ & $101.0 \pm 15.0$ & $89.0 \pm 10.0$ \\
\hline $\operatorname{Vol}\left(\mathrm{mm}^{3}\right)$ & $270.0 \pm 40.0$ & $860.0 \pm 200.0$ & $1160.0 \pm 320.0$ & $2330.0 \pm 490.0$ \\
\hline Proportion of total vol & $12 \%$ & $37 \%$ & $51 \%$ & $100 \%$ \\
\hline \multicolumn{5}{|l|}{ L4-5 } \\
\hline Height (mm) & $10.2 \pm 0.0$ & $9.1 \pm 1.8$ & $10.2 \pm 0.0$ & $29.5 \pm 1.8$ \\
\hline Area $\left(\mathrm{mm}^{2}\right)$ & $47.0 \pm 6.0$ & $110.0 \pm 14.0$ & $117.0 \pm 13.0$ & $92.0 \pm 16.0$ \\
\hline Vol $\left(\mathrm{mm}^{3}\right)$ & $480.0 \pm 60.0$ & $1010.0 \pm 290.0$ & $1190.0 \pm 130.0$ & $2740.0 \pm 620.0$ \\
\hline Proportion of total vol & $18 \%$ & $38 \%$ & $44 \%$ & $100 \%$ \\
\hline $\mathrm{p}$ value $\dagger$ & $<0.001$ & $<0.001$ & $<0.001$ & $<0.001$ \\
\hline
\end{tabular}

the IVF's lateral and medial boundaries. Some studies limit the IVF to the space between the lateral and medial borders of the pedicle. ${ }^{20,34}$ Because the posterolateral IVD and the lateral border of the IVJ are far lateral to the pedicle, in the present study we defined the lateral boundary of the IVF as a sagittal plane that passes from the posterolateral margin of the vertebral body to the most lateral aspect of the IVJ. Its parallel sagittal plane along the most lateral aspect of the dural sac was defined as the medial boundary of the IVF.

The 3D boundaries of the lumbar IVF defined in this study may have 3 advantages. 1) The newly defined IVF corresponds to the zoning of the lateral lumbar spinal ca$\mathrm{nal}^{20}$ but with a more precisely defined lateral boundary. 2) It contains all the transforaminal structures associated with commonly used transforaminal surgical or injection procedures, including the extrapedicular working zone originally described by Kambin and Brager. ${ }^{14}$ 3) It may facilitate the comparability of future studies on the 3D architecture of the IVF in both cadavers and living subjects because all the boundaries are detectable in medical imaging.

\section{Subdivisions of the Lumbar IVF}

Clinically, the IVF has been depicted as a midzone of the lateral lumbar spinal canal, which consists of the entrance zone (lateral recess), midzone (IVF), and exit zone. ${ }^{20}$ The zoning of the lateral spinal canal was based on the neural structures that come off the dural sac and terminate where the spinal nerve emerges laterally from the canal. The midzone contains the DRG and ventral root of the spinal nerve..$^{20} \mathrm{On}$ its posterolateral view, the midzone is further divided into Kambin's triangle and the safe triangle. ${ }^{2,29}$ However, both triangles as well as other transforaminal access routes described in the current literature are not defined within the midzone of the lateral spinal canal, and are expanded medially to the dural sac and laterally beyond the lateral border of the pedicle.

Considering the clinical importance of the current concepts of the lateral spinal canal and transforaminal access routes and also a better understanding of the differences in $3 \mathrm{D}$ configuration between the upper and lower lumbar IVFs, further subdivisions of the IVF were proposed in this study. In addition to the 3D boundaries of the IVF, the 


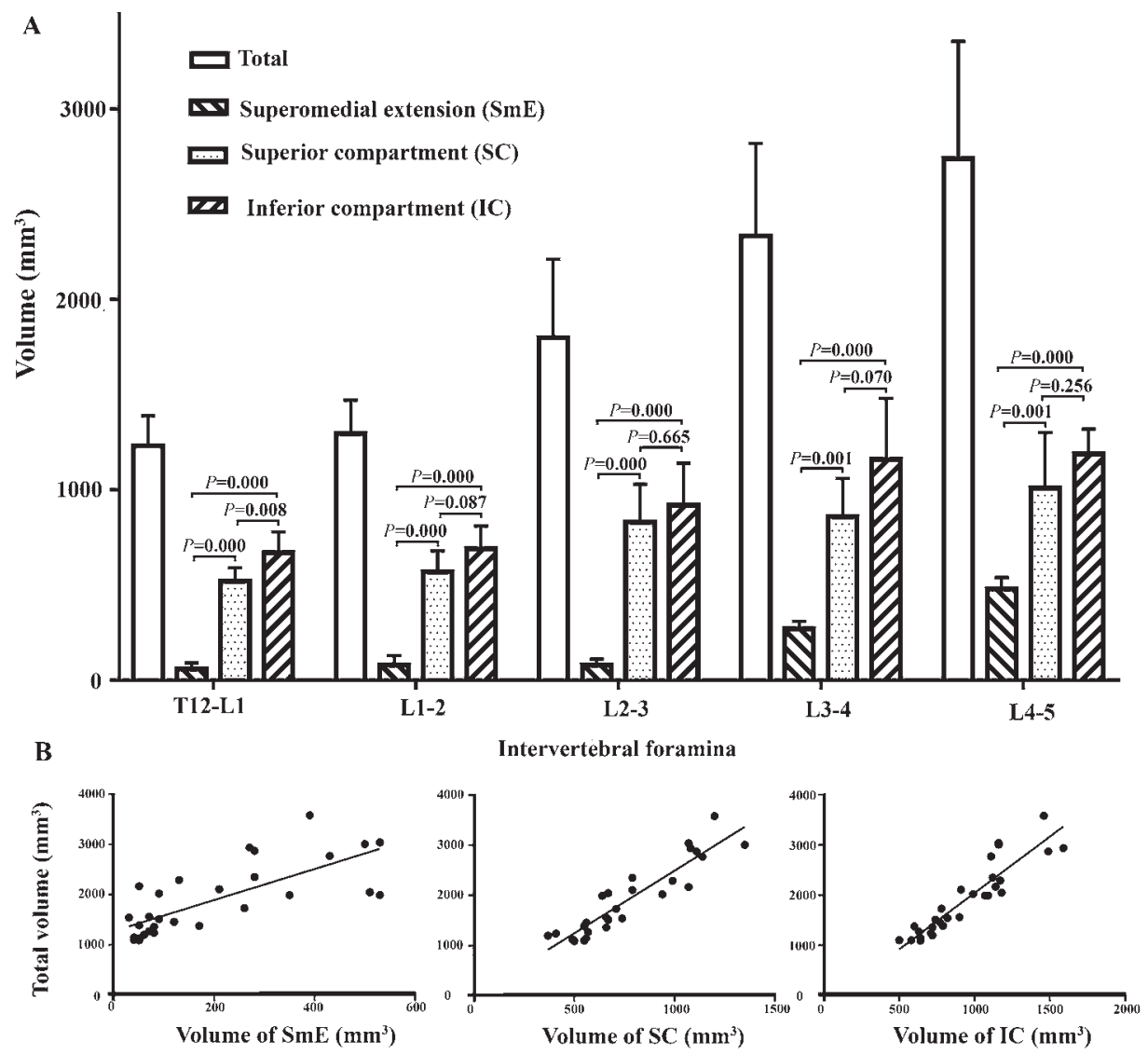

FIG. 6. Graphs showing comparisons of the volume (A) and correlation (B) between the lumbar IVFs and their subcompartments. The $p$ values are given for the comparison of the volumes among 5 IVFs (1-way ANOVA test).

inferior border of the DRG and the opening of the dural sleeve were selected as two additional landmarks. The level of the inferior border of the DRG was used to subdivide the IVF into superior and inferior compartments because the DRG in the lumbar spine is always within the foramen, and its inferior border corresponds to the level of the superior endplate of the IVD, the bifurcation of the spinal artery, and the main TFBs of the anulus fibrosus.

\section{Different Fine Architectures Between the Upper and Lower Lumbar IVFs}

The distribution and localization of the neurovascular (or "dangerous zone") and adipose (or "safe working zone") tissues within the lumbar IVF have been qualitatively and quantitatively studied in both living subjects and cadavers. Most of these studies were performed in a 2D plane $\mathrm{e}^{7,10,25}$ or limited to the space bordered by the pedicles. ${ }^{18}$ From a 3D perspective, this study systematically examined the fine architecture of the IVF and found that the 3D configuration and localization of the neurovascular and adipose zones were different between the upper and lower lumbar IVFs.

In addition to the increase in height, area, and volume of the IVF (Table 2) and the decrease in the angle between the exiting spinal nerve and the inferior endplate, ${ }^{24}$ the main different configuration of the neurovascular and adipose zones between the upper and lower lumbar IVFs appeared to be determined by the alteration of the TFB attachment. In the upper lumbar IVFs, the TFBs of the anulus fibrosus traversed the foramen and were anchored to the pars interarticularis and its neighboring structures, including the neurovascular sheaths. These TFBs further subdivided the inferior compartment into a small anteroinferior adipose pocket and a large posterosuperior neurovascular zone. In the lower lumbar IVFs, the TFBs were anchored to the anterior part of the pedicle only, and thus the whole inferior compartment was almost entirely occupied by the adipose tissue, whereas the neurovascular structures were limited within the superior compartment.

\section{Conceptualizing an Optimal Transforaminal Approach in the Upper and Lower Lumbar IVFs}

Although in general the infraneural adipose zone in a lumbar IVF gradually tapered and rotated from the inferoposterolateral aspect to the superoanteromedial aspect, zoning in the upper lumbar IVFs is much more complex than that in the lower lumbar IVFs. Therefore, the planning of an optimal transforaminal approach should be different between the upper and lower lumbar IVFs. Based on the findings of this study, we propose a theoretical strategy 
to plan an optimal transforaminal approach in these areas. 1) In general, it should always be through the inferior compartment, which is below the inferior border of the DRG or the superior endplate of the IVD. The DRG and the endplate of the IVD are detectable in preoperative medical imaging. If the posteromedial IVD is a target point, reaming the SAP is mandatory; otherwise a more lateral access is necessary. ${ }^{30}$ 2) In the upper lumbar IVF, the optimal transforaminal approach appears to be at $60^{\circ}$ without reaming the SAP (Fig. $5 \mathrm{~B}$ and F) or $30^{\circ}$ with at least partially reaming the SAP (Fig. 5C and G). 3) In the lower lumbar IVF, the optimal transforaminal approach seems to be better at $30^{\circ}$ with or without reaming the SAP (Fig. 5K), because the "nose" of the transverse process of the lower lumbar vertebra may block the approach at $60^{\circ}$ (Fig. 5J).

\section{Limitations of the Study}

The present study has at least two limitations: 1) the specimens from elderly cadavers, and 2) a small sample size for quantitative estimation. It is well known that the size of the IVF undergoes change in 3D planes under both physiological and pathological conditions, e.g., anatomical variations,${ }^{22}$ movements of the spine ${ }^{11}$ degeneration of the vertebra and IVD during aging, and osteoarthritis and other diseases. ${ }^{1}$ Therefore, the results of this study warrant further verification in living subjects, various age groups, and clinical practice.

\section{Conclusions}

This study highlights differences of fine 3D architecture of neurovascular and adipose tissues between the upper and lower lumbar IVFs, with related effects on the transforaminal approaches. The findings may contribute to optimization of the surgical approaches through the IVF at different lumbar spinal levels and may help to shorten the learning curve of the transforaminal techniques.

\section{Acknowledgments}

We thank Marlene Black from the Department of Anatomy, University of Otago, for her support on epoxy sheet plastination.

The project was funded by a University of Otago research grant (2018-2020) and the National Natural Science Foundation of China (reference no. 81671368). Z. Xu is supported by the PhD Scholarship, Department of Anatomy, University of Otago. The study was performed in accordance with our institutional ethical guidelines and approved by the institutional ethics committees (reference codes H18/026; H18/027; 20190532).

\section{References}

1. Cho PG, Ji GY, Shin DA, Ha Y, Yoon DH, Kim KN: An effect comparison of teriparatide and bisphosphonate on posterior lumbar interbody fusion in patients with osteoporosis: a prospective cohort study and preliminary data. Eur Spine J 26:691-697, 2017

2. Choi G, Pophale CS, Patel B, Uniyal P: Endoscopic spine surgery. J Korean Neurosurg Soc 60:485-497, 2017

3. Depauw PRAM, Gadjradj PS, Soria van Hoeve JS, Harhangi BS: How I do it: percutaneous transforaminal endoscopic discectomy for lumbar disk herniation. Acta Neurochir (Wien) 160:2473-2477, 2018
4. Derby R, Kine G, Saal JA, Reynolds J, Goldthwaite N, White $\mathrm{AH}$, et al: Response to steroid and duration of radicular pain as predictors of surgical outcome. Spine (Phila Pa 1976) 17 (6 Suppl):S176-S183, 1992

5. Fujiwara A, An HS, Lim TH, Haughton VM: Morphologic changes in the lumbar intervertebral foramen due to flexionextension, lateral bending, and axial rotation: an in vitro anatomic and biomechanical study. Spine (Phila Pa 1976) 26:876-882, 2001

6. Glaser SE, Shah RV: Root cause analysis of paraplegia following transforaminal epidural steroid injections: the 'unsafe' triangle. Pain Physician 13:237-244, 2010

7. Hardenbrook M, Lombardo S, Wilson MC, Telfeian AE: The anatomic rationale for transforaminal endoscopic interbody fusion: a cadaveric analysis. Neurosurg Focus 40(2):E12, 2016

8. Hasegawa T, An HS, Haughton VM, Nowicki BH: Lumbar foraminal stenosis: critical heights of the intervertebral discs and foramina. A cryomicrotome study in cadavera. J Bone Joint Surg Am 77:32-38, 1995

9. Hoogland T, Schubert M, Miklitz B, Ramirez A: Transforaminal posterolateral endoscopic discectomy with or without the combination of a low-dose chymopapain: a prospective randomized study in 280 consecutive cases. Spine (Phila Pa 1976) 31:E890-E897, 2006

10. Hurday Y, Xu B, Guo L, Cao Y, Wan Y, Jiang H, et al: Radiographic measurement for transforaminal percutaneous endoscopic approach (PELD). Eur Spine J 26:635-645, 2017

11. Inufusa A, An HS, Lim TH, Hasegawa T, Haughton VM, Nowicki BH: Anatomic changes of the spinal canal and intervertebral foramen associated with flexion-extension movement. Spine (Phila Pa 1976) 21:2412-2420, 1996

12. Jacquot F, Gastambide D: Percutaneous endoscopic transforaminal lumbar interbody fusion: is it worth it? Int Orthop 37:1507-1510, 2013

13. Kambin P: Arthroscopic microdiscectomy. Arthroscopy 8:287-295, 1992

14. Kambin P, Brager MD: Percutaneous posterolateral discectomy. Anatomy and mechanism. Clin Orthop Relat Res (223):145-154, 1987

15. Kambin P, Casey K, O'Brien E, Zhou L: Transforaminal arthroscopic decompression of lateral recess stenosis. J Neurosurg 84:462-467, 1996

16. Kambin P, Gellman H: Percutaneous lateral discectomy of the lumbar spine. A preliminary report. Clin Orthop Relat Res (174):127-132, 1983

17. Karaman H, Kavak GO, Tüfek A, Yldrm ZB: The complications of transforaminal lumbar epidural steroid injections. Spine (Phila Pa 1976) 36:E819-E824, 2011

18. Khiami F, Aziria SA, Ragot S, Pascal-Moussellard H, Richer JP, Scepi M, et al: Reliability and validity of a new measurement of lumbar foraminal volume using a computed tomography. Surg Radiol Anat 37:93-99, 2015

19. Kim M, Kim HS, Oh SW, Adsul NM, Singh R, Kashlan ON, et al: Evolution of spinal endoscopic surgery. Neurospine 16:6-14, 2019

20. Lee CK, Rauschning W, Glenn W: Lateral lumbar spinal canal stenosis: classification, pathologic anatomy and surgical decompression. Spine (Phila Pa 1976) 13:313-320, 1988

21. Lew SM, Mehalic TF, Fagone KL: Transforaminal percutaneous endoscopic discectomy in the treatment of far-lateral and foraminal lumbar disc herniations. J Neurosurg 94 (2 Suppl):216-220, 2001

22. Masharawi Y, Salame K, Mirovsky Y, Peleg S, Dar G, Steinberg N, et al: Vertebral body shape variation in the thoracic and lumbar spine: characterization of its asymmetry and wedging. Clin Anat 21:46-54, 2008

23. Mayer HM, Brock M: Percutaneous endoscopic discectomy: surgical technique and preliminary results compared to microsurgical discectomy. J Neurosurg 78:216-225, 1993 
24. Min JH, Kang SH, Lee JB, Cho TH, Suh JG: Anatomic analysis of the transforaminal ligament in the lumbar intervertebral foramen. Neurosurgery 57 (1 Suppl):37-41, 2005

25. Mirkovic SR, Schwartz DG, Glazier KD: Anatomic considerations in lumbar posterolateral percutaneous procedures. Spine (Phila Pa 1976) 20:1965-1971, 1995

26. Nash L, Nicholson HD, Zhang M: Does the investing layer of the deep cervical fascia exist? Anesthesiology 103:962-968, 2005

27. Park JW, Nam HS, Cho SK, Jung HJ, Lee BJ, Park Y: Kambin's triangle approach of lumbar transforaminal epidural injection with spinal stenosis. Ann Rehabil Med 35:833-843, 2011

28. Park KD, Lee J, Jee H, Park Y: Kambin triangle versus the supraneural approach for the treatment of lumbar radicular pain. Am J Phys Med Rehabil 91:1039-1050, 2012

29. Rivera CE: Lumbar epidural steroid injections. Phys Med Rehabil Clin N Am 29:73-92, 2018

30. Ruetten S, Komp M, Godolias G: An extreme lateral access for the surgery of lumbar disc herniations inside the spinal canal using the full-endoscopic uniportal transforaminal approach -technique and prospective results of 463 patients. Spine (Phila Pa 1976) 30:2570-2578, 2005

31. Standring S, Adams MA: Gray's Anatomy: The Anatomical Basis of Clinical Practice, ed 41. St. Louis, MO: Elsevier, 2016

32. Tumialán LM, Madhavan K, Godzik J, Wang MY: The history of and controversy over Kambin's triangle: a historical analysis of the lumbar transforaminal corridor for endoscopic and surgical approaches. World Neurosurg 123:402-408, 2019

33. Wiese M, Krämer J, Bernsmann K, Ernst Willburger R: The related outcome and complication rate in primary lumbar microscopic disc surgery depending on the surgeon's experience: comparative studies. Spine J 4:550-556, 2004

34. Xu XY, Yan ZJ, Ma Q, Chen L, Ke ZY, Chen F, et al: Clinical application of the paraspinal erector approach for spinal canal decompression in upper lumber burst fractures. J Orthop Surg Res 9:105, 2014
35. Xu Z, Tu L, Zheng Y, Ma X, Zhang H, Zhang M: Fine architecture of the fascial planes around the lateral femoral cutaneous nerve at its pelvic exit: an epoxy sheet plastination and confocal microscopy study. J Neurosurg [epub ahead of print December 7, 2018. DOI: 10.3171/2018.7.JNS181596]

36. Yeung AT, Tsou PM: Posterolateral endoscopic excision for lumbar disc herniation: surgical technique, outcome, and complications in 307 consecutive cases. Spine (Phila Pa 1976) 27:722-731, 2002

37. Zhang KH, Zhang WH, Xu BS, Dong XM, Guo L, Du LL, et al: CT-based morphometric analysis of approach of percutaneous transforaminal endoscopic lumbar interbody fusion. Orthop Surg 11:212-220, 2019

\section{Disclosures}

The authors report no conflict of interest concerning the materials or methods used in this study or the findings specified in this paper.

\section{Author Contributions}

Conception and design: M Zhang, Z Xu, Lin. Acquisition of data: $\mathrm{Z} \mathrm{Xu}$, Lin. Analysis and interpretation of data: M Zhang, Z Xu, Lin, H Zhang. Drafting the article: M Zhang, Z Xu, Lin, S Xu. Critically revising the article: M Zhang, H Zhang, S Xu. Reviewed submitted version of manuscript: S Xu. Approved the final version of the manuscript on behalf of all authors: M Zhang.

\section{Correspondence}

Ming Zhang: University of Otago, Dunedin, New Zealand. ming. zhang@anatomy.otago.ac.nz. 